\title{
Brain damage after cardiopulmonary by-pass: correlations between neurophysiological and neuropathological findings
}

\author{
MARIAN MALONE,* PAMELA PRIOR, $†$ CL SCHOLTZ \\ From the Departments of Morbid Anatomy and EEG, The London Hospital
}

SUMMARY Ischaemic lesions along cerebral arterial boundary zones were present in nine patients dying after cardiopulmonary by-pass. Their intra-operative cerebral function monitor recordings had shown at least 7 min major depression, its severity correlating with degrees of neurological deficit after operation and EEG abnormality and extent of infarction. In contrast eleven patients with normal or minimally abnormal cerebral function monitor recordings had macroscopically normal brains.

Ischaemic brain damage may complicate surgery with cardiopulmonary by-pass if, for any reason, cerebral perfusion becomes inadequate for the individual patient. Various forms of electroencephalographic (EEG) monitoring have been used for many years to give warning of impaired cerebral function during surgery. More recently an EEG monitoring device, the cerebral function monitor (CFM $\ddagger)^{12}$ has been used to simplify the task. The neurophysiological findings have been correlated with various operative factors such as blood flow during by-pass, oxygenation and temperature. ${ }^{3-9} \mathrm{~A}$ positive relationship has been demonstrated between periods of impairment of cerebral electrical activity and post-operative neurological state. ${ }^{10} 11$ Schwartz et al $^{12}$ have demonstrated the prognostic value of monitoring in 100 patients operated on at the London Hospital. They correlated the duration of episodes of depression of cerebral electrical activity, and the speed and adequacy of its recovery with the severity of post-operative neurological deficit. This was accurately predicted in $83 \%$ of patients on the

Present addresses: *Department of Histopathology, The Hospital for Sick Children, Great Ormond Street, London. †Department of Neurological Sciences, St Bartholomew's Hospital, London.

$\ddagger$ Par Medex Ltd, 16 Leyden Road, Stevenage, Herts, SG1 2BP.

Address for reprint requests: Dr PF Prior, St Bartholomew's Hospital, West Smithfield, London EC1A 7BE, UK.

Received 30 March 1981, and in revised form 1 August 1981 Accepted 8 August 1981 basis of the intra-operative CFM recordings.

The present investigation was undertaken to determine the relationship between operative CFM findings, subsequent neurological and EEG state and ultimate neuropathology in 20 patients dying with or without brain damage at some stage after cardiac surgery (and includes five patients previously reported by Schwartz et al ${ }^{12}$ ).

Materials and methods

PATIENTS

The study included all patients in The London Hospital necropsy records for the 8 years 1970-1977 in whom (1) death had occurred at any stage following cardiac surgery with cardiopulmonary by-pass, (2) adequate CFM recordings during operation were available, and (3) the brains had been subjected to neuropathological examination. Twenty patients fulfilled these criteria, nine having died with and 11 without clinical evidence of brain damage. The majority of these patients died in the first five years of this period. In the same 8 years 1022 operations with cardiopulmonary by-pass were performed by the Department of Cardio-Thoracic Surgery. The majority of the patients were undergoing valve replacement (10 of a single and six of more than one valve), three had repair of aortic or innominate aneurysms and one coronary vein grafting. There were 11 men and nine women whose ages ranged from 22-72 years (mean for the whole group 53 years; for those with brain damage 48 , and those without, 57 years). Survival after operation was between 1 day and 3 years (mean $5 \frac{1}{2}$ months) in the patients without brain damage and their deaths were attributable to cardiac disease or its complications. The patients with brain damage survived between 28 hours and 1 month (mean 19 
days) except for two with only minor neurological deficit who died after 14 months and 18 months respectively. The majority of the brain-damaged patients survived in coma or stupor, death usually being due to a combination of factors with cardiac disease sometimes complicated by renal and hepatic failure.

ANAESTHETIC AND BY-PASS TECHNIQUE Anaesthesia was induced with thiopentone, phenoperidine and pancuronium, maintained with nitrous oxide and further doses of pancuronium and phenoperidine and supplemented with halothane as necessary. Cardiopulmonary by-pass was provided by a Pemco heart-lung machine using a Kay-Cross disc oxygenator for cases up to 1973. After that date disposable "Temptol" bubble oxygenators (Bentley Labs Inc) were used. The pump flow rate was maintained at $2 \cdot 4 \mathrm{litre} / \mathrm{m}^{2}$ body surface area. Perfusion pressure was maintained between 6.6 and $13 \cdot 33 \mathrm{kPa}(50-100 \mathrm{mmHg})$ either by adjustment of the pump or by use of vasoconstrictor or vasodilator drugs as appropriate. Patients were cooled to between 28 and $30^{\circ} \mathrm{C} . \mathrm{PaO}_{2}$ was maintained between 13 and $26 \mathrm{kPa}$ and $\mathrm{PaCO}_{2}$ between 4 and $6 \mathrm{kPa}$ after correction for temperature.

\section{NEUROPHYSIOLOGICAL RECORDINGS}

For CFM monitoring, which was often continued over the first night after operation and longer if the patient was not fully conscious, two recording electrodes derived a signal from the left and right parietal regions of the scalp. A third electrode more anteriorly reduced electrical interference. Depression of the intra-operative CFM trace not attributable to moderate hypothermia or increased anaesthetic depth (both usually leading to a gradual and partial fall in level) was considered abnormal. ${ }^{12}$ The minimum amplitude reached, the duration of severe depression and the time taken to recover to the previous level were recorded by one author (PFP) without knowledge of the neuropathological assessment.

Full EEGs were taken at the bedside after operation in eight of the nine patients with clinical evidence of brain damage, the remaining patient being followed with CFM alone. No EEGs were made in those without neurological abnormalities. A total of 28 EEGs was available, that is a mean of 3.5 per patient, at intervals up to 4 weeks after operation. Eight-channel portable apparatus and 19 electrodes were used. Twenty-minute recordings included testing the effect of auditory, tactile and painful stimuli as appropriate.

\section{NEUROLOGICAL ASSESSMENT}

Level of consciousness, focal neurological deficits and occurrence and type of any seizures were noted at the time of follow-up EEG examinations and also from examinations by members of the Departments of Neurology or Neurosurgery.

NEUROPATHOLOGICAL EXAMINATIONS

This was made by two of the authors (MM and CLS) independently of the assessment of neurophysiological data. The brains were assessed for the presence of areas of infarction in photographs of the original coronal slices and their macroscopic descriptions. Since on inspection the damage was confined to the boundary zones between the territories of the major cerebral arteries, its severity was graded on a scale based on the degree of anterior extension of the lesions.

Grade 0 - no macroscopic abnormality.

Grade 1-boundary zone lesions in the neocortex around the parieto-occipital sulci only, that is at the junction between the territories of the anterior, middle and posterior cerebral arteries.

Grade 2-boundary zone lesions as in grade 1, but with extension anteriorly as far as the central sulcus along the anterior/middle cerebral artery boundary zones or along the middle/posterior cerebral artery boundary zones, or both of these zones.

Grade 3-neocortical boundary zone lesions as in grade 2 but with extension into the frontal lobe, with or without a lesion or lesions in areas other than the cerebral cortical boundary zones (that is in the cerebellum).

Those brains showing macroscopic abnormality (grades 1,2 or 3 ) were examined microscopically in paraffin sections $(8-10 \mu)$ stained with haematoxylin and eosin, Luxol fast blue counterstained with cresyl fast violet and lead haematoxylin. Blocks from each hemisphere included four of the neocortex (frontal, parietal, occipital and temporal lobe including the hippocampus), the basal ganglia, the brain stem and the cerebellum. The brains showing no macroscopic abnormality (grade 0 ) were not examined microscopically.

\section{Results}

Operative CFM monitoring was uneventful (showing only the appropriate minor alterations attributable to onset of by-pass, changing levels of anaesthesia and hypothermia) in seven of the 11 patients without clinical evidence of brain damage. Of the remainder, three showed partial (minimum level 3-4 microvolts) transient depressions (fig 1) and one a low level (2-4 microvolts) tracing which was unchanged before, during and after uncomplicated by-pass for replacement of mitral and tricuspid valves.

The mean time on by-pass (table 1) was $131 \pm 50$ minutes for the 11 patients without damage and $181 \pm 64$ minutes for the nine with brain damage (difference significant with Student's $t$ test $\mathrm{p}<0.05$ ).

Periods of major depression of the CFM trace (lower margin $2 \frac{1}{2}$ microvolts or less) lasting at least 7 min (figs 2 and 3 ) occurred in all the nine patients with clinical evidence of brain damage. These alterations were of rapid onset taking less than 2 min to reach the minimum level at or near to the zero microvolt baseline. The duration of the depression and the time taken for the trace to recover to its previous level are given in table 1. In the most severely damaged patients the very low voltage 
:

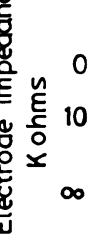
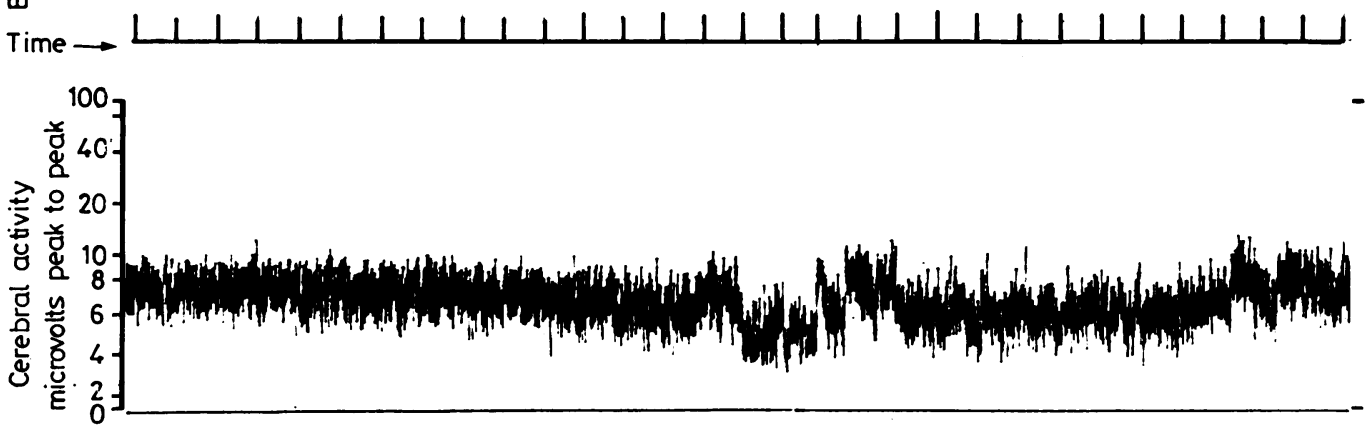

Events

Fig 1 Operative CFM trace (30 min sample) in case 16, a women of 51 yr in whom aortic and mitral valve replacement had just been completed. At the arrow blood pressure fell to $20 / 0 \mathrm{mmHg}$ for I min. This was followed by an abrupt fall in the minimum level of the CFM trace to $4 \mu v$. After about $2 \frac{1}{2}$ min the level began to rise. There was no neurological deficit post-operatively and the brain was subsequently found to be normal.

Table 1 Relationship between operative, postoperative, and neuropathological findings

\begin{tabular}{|c|c|c|c|c|c|}
\hline \multirow{2}{*}{$\begin{array}{l}\text { Time on by-pass } \\
\text { (mins) }\end{array}$} & \multicolumn{2}{|l|}{ Operative CFM } & \multicolumn{2}{|c|}{ Post-operative state } & \multirow{2}{*}{$\frac{\text { Brain damage }}{\text { Grade and }(n)}$} \\
\hline & Depression $(n)$ & Recovery (n) & $E E G(n)$ & Neurological $(n)$ & \\
\hline $131 \pm 50$ & $\begin{array}{l}\text { none }(7) \\
\text { minor }(3) \\
\text { low level (1) }\end{array}$ & immediate (3) & no EEGs & normal (11) & $0(11)$ \\
\hline $171 \pm 62$ & $>7 \min (2)$ & $>15 \min (2)$ & $\begin{array}{l}+ \text { or } t+ \\
\text { (1) (1) }\end{array}$ & $\begin{array}{l}\text { coma } \rightarrow \text { stupor }(1) \\
\text { slow to wake } \rightarrow \\
\text { dementia }(1)\end{array}$ & $1(2)$ \\
\hline $169 \pm 67$ & $9-47 \min (4)$ & $\begin{array}{l}6 \text { min (1)-several } \\
\text { hours (3) }\end{array}$ & $\begin{array}{l}t+t \text { or } \\
\text { (3) }\end{array}$ & $\begin{aligned} & \text { coma } \rightarrow \text { stupor }(3) \\
& \rightarrow \text { waking }(1) \\
&+ \text { partial seizures }(2) \\
& \text { or local deficit }(1)\end{aligned}$ & $2(4)$ \\
\hline $212 \pm 46$ & $>17 \min (3)$ & $\begin{array}{l}40 \text { min }(1)- \\
\text { persistent } \\
\text { depression (2) }\end{array}$ & $\begin{array}{l}+++ \\
(3)\end{array}$ & $\begin{array}{l}\text { persistent coma (3) } \\
+ \text { seizures (1) }\end{array}$ & $3(3)$ \\
\hline
\end{tabular}

electrical activity persisted in follow-up CFM recordings and intermittent EEGs were, or gradually became, isoelectric.

There were identifiable causes for most of the periods of depression of the CFM trace in patients with and without subsequent brain damage. In the former these included haemorrhage leading to profound hypotension just before by-pass in a patient with ruptured aortic aneurysm, transient low perfusion pressures and ventricular fibrillation. Conversely some similar events occurred in both groups of patients which might have been expected to impair cerebral perfusion but did not lead to any depression of the CFM trace. In the patients not sustaining brain damage the periods of partial depression of electrical activity were related to lesser falls in arterial blood pressure or by-pass pressures presumed to be inadequate for the particular patient. In these, rapid recovery of cerebral activity followed appropriate corrective procedures. No major falls in level of the CFM trace occurred at the time of onset or termination of by-pass in any patient. 


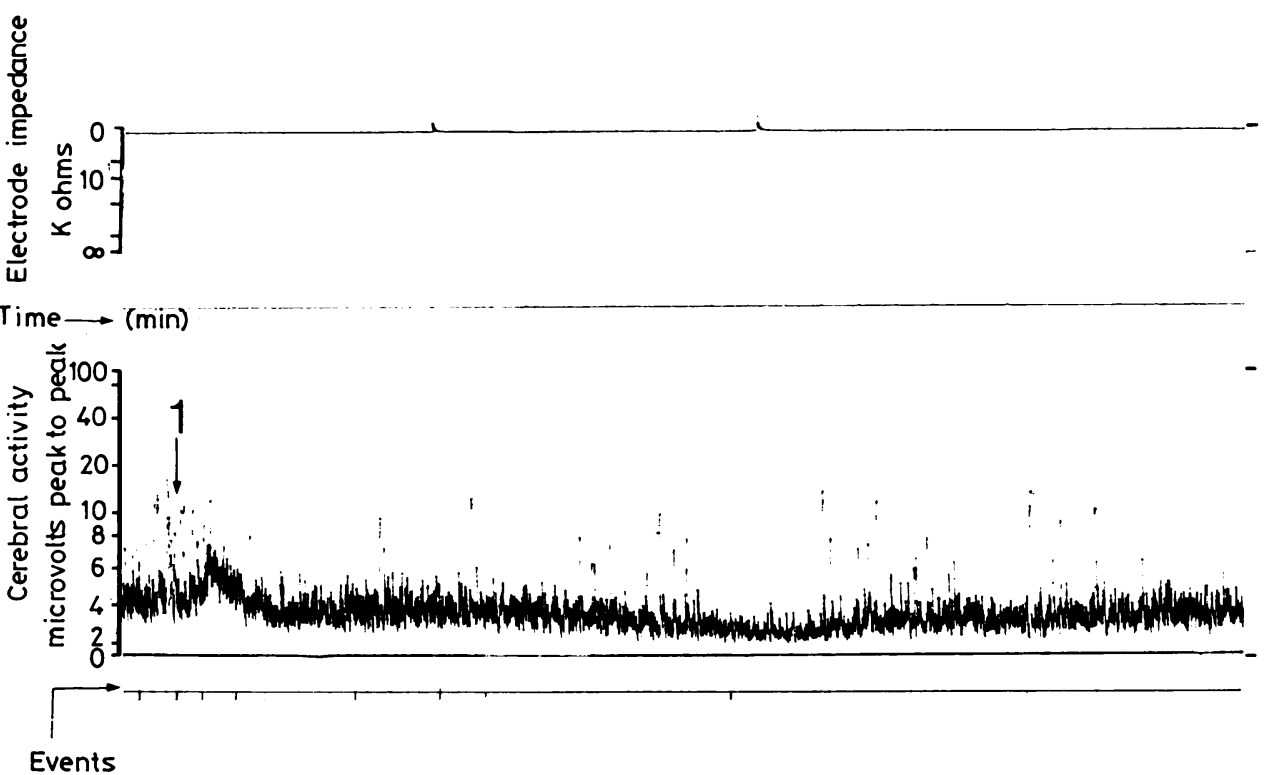

Fig 2 Operative CFM trace (30 min sample) in case 9, a man of 30 undergoing mitral and tricuspid valve replacement. At the arrow (I) haemorrhage led to a mean arterial pressure of $50 \mathrm{mmHg}$. At the time of the subsequent 4 events marks (see bottom trace) by-pass began and arterial pressure rose to $60 \mathrm{mmHg}$, then fell to zero, rose again to $60 \mathrm{mmHg}$, then remained at $50-60 \mathrm{mmHg}$. The patient was slow to wake and exhibited a permanent intellectual deficit until his death from heart failure 18 months later (11 days after reoperation which was uneventful as far as cerebral activity and neurological state were concerned). Grade 1 boundary zone lesions were present (see fig 7).

Table 2 Types of EEG abnormality in patients with arterial boundary zone ischaemic lesions

\footnotetext{
1 Selective reduction of activity (amount and voltage) posteriorly, best seen in a bipolar transverse montage.

2 Asymmetries - of background activities, flattening, slow waves or transients.

3 Focal abnormalities, often bilateral and independent-seizure discharges, slow waves (delta frequency) typically seen in parasagittal regions (fronto-parietal).

4 Bifrontal monorhythmic delta bursts.

5 Responses to stimuli reduced or abnormal (paradoxical slow wave responses ${ }^{25}$ ) or absent.
}

The serial post-operative EEG studies were begun whilst the patients were in coma. All showed clearcut abnormalities, generally widespread and with multifocal features usually maximal in the parietooccipital regions and with parasagittal emphasis. They included one or more of the signs in table 2 . The abnormalities were graded + if one,++ if $2-4$ and +++ if all these abnormal signs were present or if the EEG was isoelectric, (table 1). In three patients prominent asymmetry or focal features were present consisting of reduction of all left hemisphere activities (No 11 with a right hemiparesis) and focal seizure discharges (Nos 13 and 14 with appropriately lateralised focal seizures). In some patients with moderate or light levels of coma, clear EEG responses to external stimuli were present when motor responses were either absent or masked by sedatives or muscle relaxants.

Neurological examination remained abnormal in all patients in whom brain damage was demonstrated neuropathologically, but was unremarkable in those with normal brains (table 1). Neuropathological examination demonstrated that the brains of the 11 patients dying without clinical evidence of brain damage did not contain any macroscopic abnormality. The brains of the nine patients with clinical evidence of brain damage all showed boundary zone lesions characterised by asymmetric areas of laminar cortical necrosis greater within sulci than over gyri and with only superficial involvement of white matter. The asymmetries were minor and showed no constant lateralisation. The severity of the lesions was unrelated to the age of the patients. The boundary zone lesions involved the cerebral cortex in all patients. No other cortical lesions were encountered. Outside the cerebral cortex, boundary zone lesions were also seen in the cerebellum (patient No 5) 


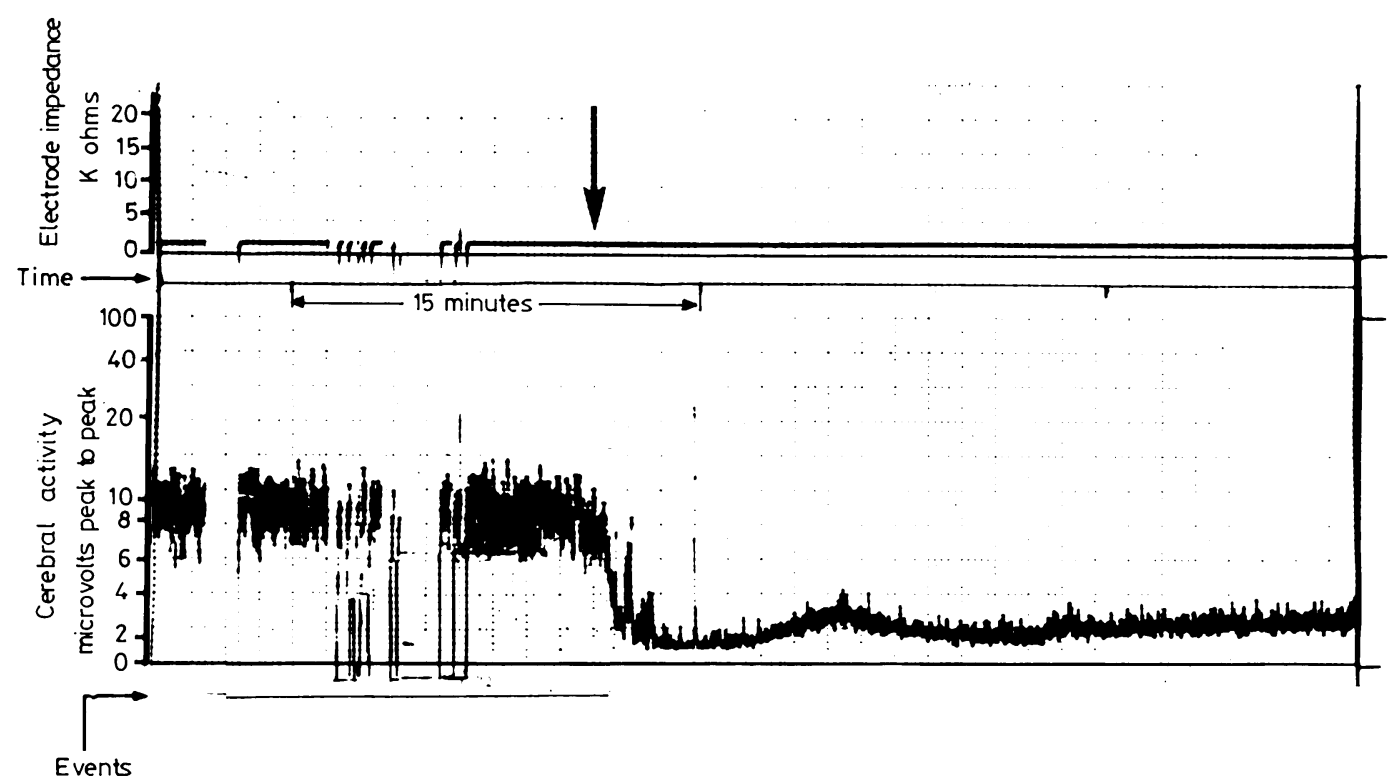

Fig 3 Operative CFM trace (45 min sample) in case 11, a man of 52 undergoing mitral valve replacement 5 years after previous aortic and aortic valve surgery. At the arrow, just before full by-pass, haemorrhage led to a fall in level of the CFM trace to a minimum of I-2 microvolts. Immediate full by-pass and cooling to $26^{\circ} \mathrm{C}$ followed. The trace remained near baseline for over 47 min then activity slowly increased over 2 hours. Initial coma improved to stuporase state with right hemiparesis. Death occurred after 1 month: grade 2 boundary zone lesions were more extensive on the left; the cutouts to below zero are due to diathermy (illustration reproduced with permission of the publisher from preliminary report, 2).

between the territories of the superior and posterior cerebellar arteries.

Although three patients (Nos 11, 13 and 14) showed clinical and EEG evidence of lateralised or asymmetric neurological problems, in only one (No 11, with a right hemiparesis) was this associated with clear asymmetry of the bilateral boundary zone lesions. In the two with focal seizures (Nos 13 and 14) lesions showed only minor asymmetry. No patient had evidence of occlusive vascular disease in extra or intracranial cerebral vessels.

In three patients (Nos 5, 10 and 14) there was both macroscopic and microscopic evidence of sharp demarcation between the normal and the infarcted tissue in some of the boundary zone lesions (fig 4). No debris was found in adjacent blood vesseis. In case 5 the CFM level had fallen at the time of ventricular fibrillation at the start of rewarming. The possibility of a coincident small air embolism was noted. There was nothing to suggest gaseous embolism however in cases 10 and 14 .

The microscopic appearances of boundary zone lesions depended on the length of survival time following the operation. In the two patients (Nos 8 and 14) dying between 28 hours and one week there was a spongy state or ischaemic cell change at the homogenising stage. The cytoplasm stained violet with Luxol fast blue and pink with eosin. Small round cell infiltration was minimal. Seven days after the episode the lesions were characterised by a

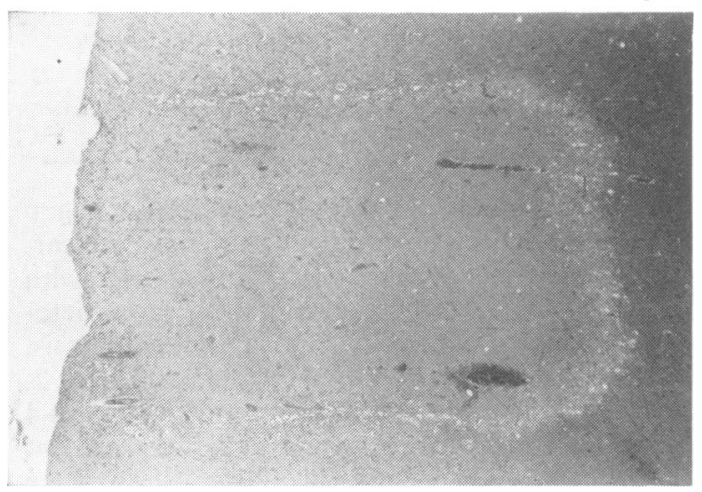

Fig 4 Low power view of necrosis with sharp demarcation within the occipital lobe boundary zone area from case 10 (survival 4 weeks). Haematoxylin and eosin $\times 18$. 
gliomesodermal reaction composed of small blood vessels and proliferating astrocytes in a meshwork of collagen and reticulin fibres. The degenerate neurones were surrounded by lipid-filled macrophages. This reaction primarily involved layers 3 and 5 with some extension into the superficial white matter. In the five patients dying between one week and $7 \frac{1}{2}$ weeks the gliomesodermal reaction was more pronounced (fig 5). The blood vessels were more prominent and tortuous with proliferation of the endothelial cells. Where survival was in excess of one year (two patients, Nos 9 and 13) the cortex at the site of the boundary zone lesions was replaced by a narrow band of small vessels and glia with marked cortical atrophy (fig 6). In some of these patients (No 13) with two operations histological features could be related to both of these ( 14 months and 3 days).

In patient No 11 ischaemic damage similar to that

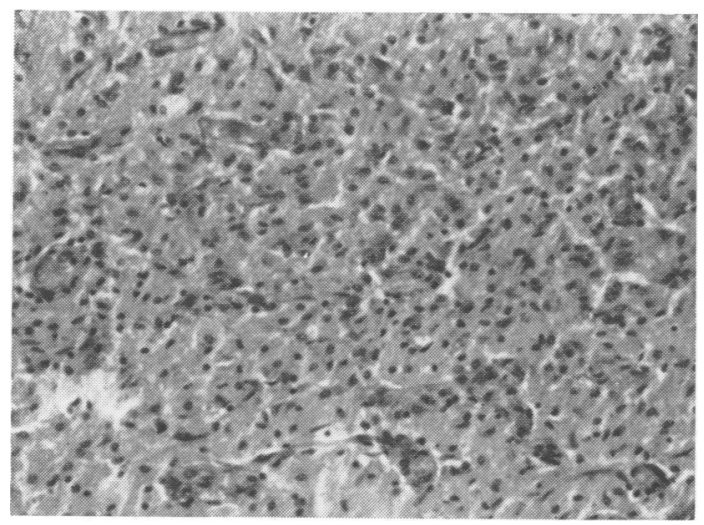

Fig 5 Gliomesodermal reaction in the boundary zone of the frontal lobe from case 7 (survival 17 days). Haemato$x y$ lin and eosin $\times 153$.

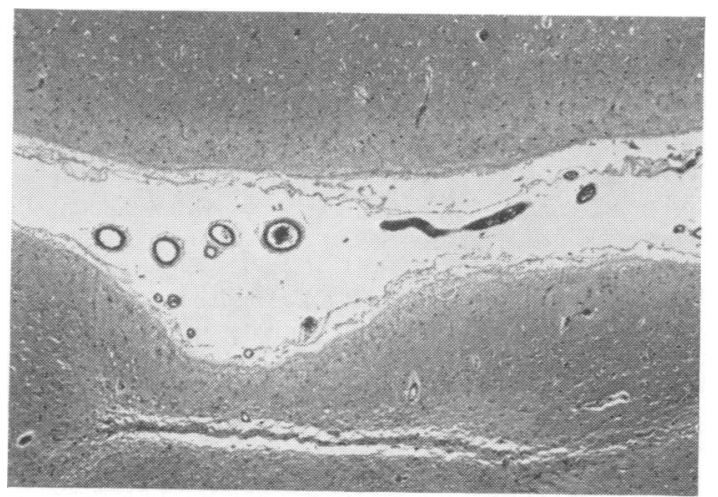

Fig 6 Slit-like band of necrosis with gliosis in the posterior parietal region of the boundary zone area from case 9 (survival 18 months). Haematoxylin and eosin $\times$ 58 . in the cortex was also seen in the Sommer sector of the hippocampus. This patient had grade 2 boundary zone lesions.

\section{Discussion}

This retrospective study has demonstrated correlations between neurophysiological, clinical and neuropathological aspects of ischaemic brain damage complicating cardiopulmonary by-pass. It has indicated that neuronal damage was always preceded by at least $7 \mathrm{~min}$ of near or complete electrical silence during the period of presumed cerebral hypoperfusion. Lesser periods of depression of electrical activity were associated with full clinical recovery and a macroscopically normal brain, both externally and on section. We are aware that unavailability of blocks for microscopy in these 11 patients restricts the value of these observations. All nine patients with clinical evidence of brain damage exhibited macro-and microscopic evidence of infarcts concentrated along the arterial boundary zones. The extent of the brain lesions was related to the duration and severity of impairment of the operative CFM trace and its subsequent rate and degree of recovery. The EEGs after operation, with their characteristic features, gave confirmation of the likely severity and also indicated the distribution of brain damage with its typical posterior and parasagittal emphasis.

The duration of by-pass was significantly related to occurrence of brain damage being most prolonged in the patients with severe lesions. Sotaniemi ${ }^{13}$ in a study of 100 patients has shown that the incidence of brain damage rises from $19.6 \%$ to $51.9 \%$ (independent of age of patients) when by-pass times of less and more than 2 hours are compared. This may merely reflect surgical complexity rather than any direct effect of prolonged by-pass per se.

The neuropathological examination has shown arterial boundary zone ischaemic lesions similar in site to those produced experimentally in the Rhesus monkey by profound hypotension. ${ }^{14}$ These are also encountered in a wide range of clinical settings. ${ }^{15}$ Boundary zone infarcts occur at the junction of the territories of anterior, middle and posterior cerebral arteries when there is oligaemic hypoxia due to reduced perfusion. These boundary zones are at the points most distal to the origin of each major cerebral artery. As systemic blood pressure falls they will be the first regions in which flow is reduced to a critical level. ${ }^{16}$ It was observed in the present study that the minimal lesions were confined to the parietooccipital regions and more extensive lesions always extended anteriorly into the temporal and frontal lobes.

The distribution of ischaemic lesions in the 
arterial boundary zones following episodes of reduced cerebral perfusion represents a pathological picture distinct from that following total circulatory arrest. In the latter selective neuronal necrosis generally affects the cortex more diffusely and also involves the hippocampus, thalamus, basal ganglia and cerebellum. The histological features of ischaemic damage in both processes are similar and consist of ischaemic cell change and the corresponding gliomesodermal reaction. ${ }^{17}$ There was no evidence of diffuse neuronal loss in the brains of the nine patients examined microscopically. The limitation of examination of small rather than large blocks makes it impossible to exclude any diffuse change completely. However all cortical areas not involved in the boundary zone lesions were normal, as were the hippocampal and basal ganglia blocks. There is of course no information on this point in the 11 patients whose brains were normal macroscopically but not examined microscopically.

Asymmetries of minor degree were present in all the boundary zone lesions but only marked in the one patient with hemiparesis (case 11). The usual cause of such asymmetry is lateralised vascular occlusion $^{18}$ or a congenital vascular anomaly. However we could not implicate these causes, indeed focal occlusive vascular disease was not present in any of our patients, nor was there any correlation between age of the patient and the severity of lesions. A right hemisphere preponderance of clinically assessed damage has been reported ${ }^{13}$ but was not evident in the present series. In our patients the bilateral nature of lesions in all the damaged patients was notable and although asymmetries were present they were minor and not constantly lateralised. In only the one patient with a hemiparesis was there a marked (and appropriate) asymmetry but even so the boundary zone lesions were clearly bilateral.

When cardiac surgery involves by-pass air embolism may occur and produce ischaemic damage also along the boundary zones but often characterised by a well-marked geographical outline. ${ }^{19} 20$ In the present series clearly defined geographical damage was seen histologically in some of the lesions in three patients but there was no neurophysiological evidence of cerebral disturbance at the times most likely for the occurrence of air emboli, that is at the onset and termination of by-pass. In one (case 5) the possibility of a small air embolism at the time of ventricular fibrillation arose. There was almost invariably evidence of a possible cause for reduced cerebral perfusion at the time of the periods of electrical silence whether or not this was sufficient to lead to ischaemic brain damage. In spite of this it would be impossible to exclude some contribution of small air emboli in addition to the known episodes of hypoperfusion in the genesis of these boundary zone lesions.

An association was demonstrated between a sustained period of major depression of cerebral electrical activity (at least $7 \mathrm{~min}$ near or complete electrical silence) and ischaemic brain damage. Shorter periods, however, were not associated with damage, in accordance with experimental studies on ischaemic lesions. ${ }^{21}$ This forms the rationale for routine monitoring of electrical activity to give warning of the onset of significant cerebral ischaemia so that appropriate action can be taken before permanent damage is sustained. Experimental evidence in the baboon confirms the relationship between the total period of electrical depression during reduced cerebral perfusion and subsequent rate of recovery and the extent of boundary zone ischaemic lesions. ${ }^{22}$ Patients particularly at risk are those with, often unsuspected, occlusive vascular disease affecting extra or intracranial vessels in whom a period of reduced perfusion may precipitate cerebral infarction. ${ }^{23} 24$ During surgical procedures under general anaesthesia when cerebral perfusion is reduced deliberately or accidentally the only means of detecting a fall to a critical level for the brain is by some form of direct and continuous monitoring of the functional state of the brain. The present study $\mathbb{\Phi}$ indicates that the parieto-occipital region is the most 0 sensitive site for recording electrodes since this is where the minimal boundary zone ischaemic lesions occur and where such lesions attain their maximal severity and extent. If monitoring from this site indicates an impairment of that cerebral activity, urgent action to improve cerebral perfusion is indicated and may obviate the complication of ischaemic brain damage.

We thank Mr EJM Weaver and Dr MP Colvin for permission to report details of patients under their care, Professor $\mathbf{H}$ Urich for access to his original neuropathological data and Professor CL Berry, Drs JB Brierley, DE Maynard and DF Scott for advice.

\section{References}

${ }^{1}$ Maynard D, Prior PF, Scott DF. Device for continuous monitoring of cerebral activity in resuscitated patients. Br Med J 1969;4:545-6.

2 Prior PF. Monitoring Cerebral Function. Amsterdam: Elsevier/North Holland, 1979:1-366.

${ }^{3}$ Arfel G, DuBouchet N. Repercussions electroencéphalographiques de l'arrêt circulatoire sous hypothermie. Anesthésie, analgésie, réanimation 1963;20: 17-27.

${ }^{4}$ Fischer-Williams M, Cooper RA. Some aspects of electroencephalographic changes during open heart 
surgery. Neurology (Minneap) 1964;14:472-82.

${ }^{5}$ Harden A. Effects of arterial and venous pressure changes on the electroencephalogram during cardiac operations. $\mathrm{Br} \mathrm{Med} J \mathrm{I} 1965$;1:23-7.

${ }^{6}$ Junega I, Flynn RE, Berger RL. The arterial and venous pressures, and the electroencephalogram during open-heart surgery. Acta Neurol Scand 1972; 48:163-8.

' Wright JS, Lethlean AK, Hicks RG, Torda TA, Stacy R. Electroencephalographic studies during openheart surgery.J Thorac Cardiovasc Surg 1972;63:631-8.

${ }^{8}$ Branthwaite MA. Factors affecting cerebral activity during open-heart surgery. Anaesthesia 1973;28:61925.

${ }^{9}$ Reilly EL, Brunberg JA, Doty DB. Effect of deep hypothermia and total circulatory arrest on the electroencephalogram in children. Electroencephalog Clin Neurophysiol 1974;36:661-7.

${ }^{10}$ Branthwaite MA. Detection of neurological damage during open-heart surgery. Thorax 1973;28:464-72.

11 Branthwaite MA. Prevention of neurological damage during open-heart surgery. Thorax 1975;30:258-61.

${ }_{12}$ Schwartz MS, Colvin MP, Prior PF et al. The cerebral function monitor. Its value in predicting the neurological outcome in patients undergoing cardiopulmonary by-pass. Anaesthesia 1973;28:611-8.

${ }^{13}$ Sotaniemi KA. Brain damage and neurological outcome. J Neurol Neurosurg Psychiatry 1980;43:12735.

14 Brierley JB, Brown AN, Excell BJ, Meldrum BS. Brain damage in the Rhesus monkey resulting from profound arterial hypotension. I, Nature, distribution and general physiological characteristics. Brain Res $1969 ; 13: 68-100$.

${ }^{15}$ Graham DI. Pathology of hypoxic damage in man. In: Morson BC, ed. Hypoxia and Ischaemia. J Clin Path 30, Supplement (Royal College of Pathologists) 1977; $11: 170-80$.
${ }^{16} \mathrm{Zülch} \mathrm{KJ}$, Behrend $\mathrm{RCH}$. The pathogenesis and topography of anoxia and ischaemia of the brain in man. In: Gastaut H, Meyer JS, eds. Cerebral Anoxia and The Electroencephalogram. Illinois: Thomas, 1961 :144-63.

${ }^{17}$ Brierley JB. Cerebral hypoxia. In: Blackwood W, Corsellis JAN, eds. Greenfield's Neuropathology. 3rd ed. London: Arnold, 1976:43-85.

${ }^{18}$ Romanul FCA, Abramowicz A. Changes in brain and pial vessels in arterial border zones. Arch Neurol 1964;11:40-65.

19 Brierley JB. Neuropathological findings in patients dying after open-heart surgery. Thorax 1963;18:291304.

${ }^{20}$ Brion S, Psimaras A, Gallissot MC. Neuropathologie de l'embolie gazeuze humaine au cours de la chirurgie cardiaque. In: Arfel G, Naquet R, eds. L'Embolie Gazeuze du Systeme Carotidien. Paris: Doin, 1974: 194-8.

${ }^{21}$ Morawetz RB, Crowell RH, DeGirolami U, Malcoux FW, Jones JH, Halsey JH. Regional cerebral blood flow thresholds during cerebral ischemia. Fed Proc 1979;38:2493-4.

${ }^{22}$ Brierley JB, Prior PF, Calverley J, Jackson SJ, Brown $\mathrm{AW}$. The pathogenesis of ischaemic neuronal damage along the cerebral arterial boundary zones in Papio anubis. Brain 1980;103:929-65.

${ }^{23}$ Yates PO, Hutchinson EC. Cerebral infarction: the role of stenosis of the extracranial cerebral arteries. MRC Special Report Series No. 300. London: HMSO, 1961:1-95.

${ }^{24}$ Ross Russell RW, Bharucha N. The recognition and prevention of border zone cerebral ischaemia during cardiac surgery. $Q J$ Med 1978;47:303-23.

${ }^{25}$ Schwartz MS, Scott DF. Pathological stimulusrelated slow wave arousal responses in the EEG. Acta Neurol Scand 1978;57:300-4. 